\title{
Australia takes university cash to pay for research facilities
}

\section{But overall flat science funding in latest budget is seen as a reprieve after last year's heavy cuts.}

\section{David Cyranoski}

13 May 2015

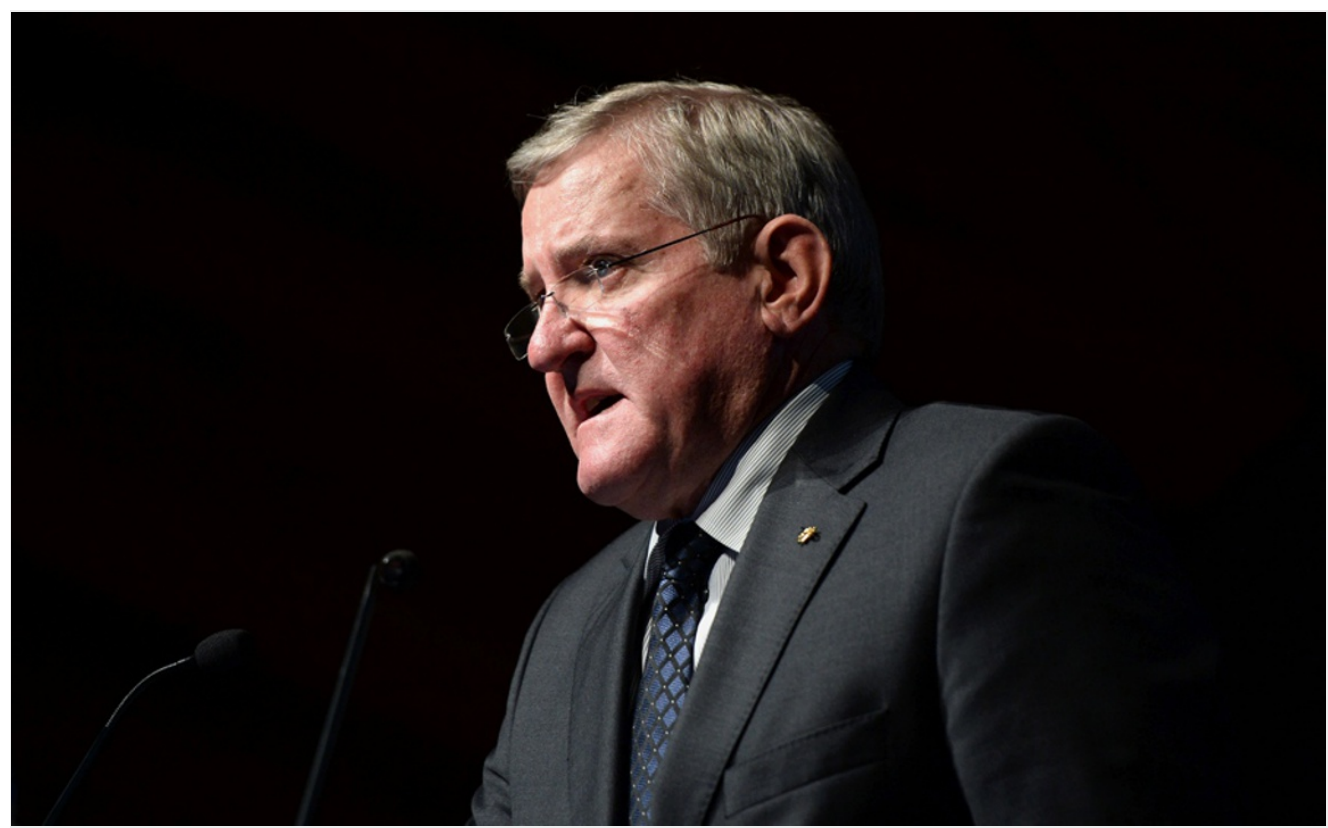

Carla Gottgens/Bloomberg/Getty

lan Macfarlane, Australia's industry and science minister, says the budget is intended to create stronger connections between research and industry.

Australia's government is removing funding from university grants to keep key national research facilities running, its latest budget reveals.

The nation's 2015-16 annual budget, released on 12 May, was met with concern from university heads who say that they are increasingly uncertain about the sustainability of the tertiary education system after a few years of funding cuts and job losses. "The current system for funding universities in Australia is broken," says Vicki Thomson, chief executive of the Group of Eight, which represents Australia's most research-intensive universities. "It can't support continued expansion of access to university education while maintaining quality, and it can't fund research adequately."

The transfer was made to save the National Collaborative Research Infrastructure Strategy (NCRIS), which covers 27 facilities employing 1,700 staff, and supports disciplines ranging from astronomy to materials research. Earlier this year, many of the facilities faced closure, but pressure from researchers persuaded the government to provide Aus $\$ 300$ million (US $\$ 243$ million) — enough for another two years of operation.

That cash, the budget shows, will be taken mostly from grants given to universities to pay for indirect costs related to research. They will be cut by Aus $\$ 263$-million over the next three years. "Funding research infrastructure by cutting funding to the researchers who use it simply doesn't make sense," says Andrew Holmes, president of the Australian Academy of Science.

Belinda Robinson, chief executive of Universities Australia in Canberra, a body representing Australia's 39 universities, says that because many businesses and state government agencies also use NCRIS, "there can be no justification for the financial burden to be borne exclusively by the universities".

\section{Relief after cuts}

Overall, researchers have grudgingly accepted the science budget, which is flat relative to last year's, as a reprieve after years of funding cuts and job losses. Particularly painful was last year's Aus\$115-million cut to the nation's premier science agency, the 
Commonwealth Scientific and Industrial Research Organization (CSIRO), which led to hundreds of staff being let go and the remaining researchers deciding to take industrial action on 30 April.

The Aus $\$ 9$-billion science budget included some perks: Aus $\$ 20.5$ million for the Australian Synchrotron in Melbourne (guaranteeing an extra year's operations in 2016-17), and a Aus\$15.4-million boost over the next four years for a new programme to research tropical diseases. A 'future fellowships' fund, which supports Australia's brightest mid-career scientists, had been feared dead, but it is expected that around half the normal number of some 150-200 fellowships will be funded.

Researchers were also happy to see the first financial support from the Medical Research Future Fund, an Aus $\$ 20$-billion-dollar initiative to support biomedical research announced last year. Its launch was delayed after controversy over plans to finance the scheme by charging people to visit family doctors. Australia's government abandoned that idea in December, and will instead rely on making savings in the nation's health-care budget. To get the fund started, this year's budget will distribute Aus $\$ 10$ million to researchers this year by 1 August, and promises to disburse more than Aus $\$ 400$ million over the next four years.

Darren Saunders, a cancer researcher at the Garvan Institute in Sydney, says that the medical-research fund is a "light at the end of the tunnel" after declining budgets and falling success rates for applications. "I am desperately trying to hang on long enough to benefit from this scheme," he says.

In an online statement, minister for science and industry lan Macfarlane said that the budget reflected the government's strategic aim to "create stronger connections between research and industry and maximise Australia's competitiveness". But some say that this aim has been inconsistently applied in the budget. Cooperative research centres that are meant to bridge university research with industry will be cut by Aus $\$ 26.8$ million.

To many, any talk of funding 'strategy' is a misnomer. "So far, we haven't seen any strategy, just cuts with promises of a strategy to come," says Holmes.

"Spending or cutting without an overarching strategy has been a hallmark of science policy since I have lived in Australia," says Brian Schmidt, a Nobel-prizewinning astronomer at the Australian National University in Canberra.

Nature | doi:10.1038/nature.2015.17556 